\title{
INFORMACIONI SISTEM ZA KONTROLU LETENJA BESPILOTNIH VAZDUHOPLOVA
}

\author{
Dragan Vasiljević ${ }^{1}$ \\ Julijana Vasiljević1, \\ Aleksandar Đurić2 \\ Ivan Pavlović2 \\ ${ }^{1}$ University of Nis, \\ Faculty of Electronic Engineering, \\ Nis, Serbia \\ ${ }^{2}$ Ministarstvo odbrane RS
}

\begin{abstract}
Rezime:
S obzirom na to da je ekspanzija upotrebe bespilotnih vazduhoplova obeležje savremenog, aktuelnog doba, iskustva o svim aspektima njihovog angažovanja i ukupnom uticaju istih na bezbednost vazdušnog saobraćaja još se prikupljaju i sistematizuju. Iz ugla teme ovog rada naročito je interesantna pojava specifičnog ponašanja operatera bespilotnih vazduhoplova, koje se ogleda $u$ potpunom ili delimičnom gubitku veze svesti sa realnošću, slično strastvenim konzumentima računarskih igara.

Tema ovog rada jeste prikaz integrisanog informacionog sistema za praćenje i kontrolu letenja bespilotnih vazduhoplova.

Cilj uspostavljanja navedenog sistema jeste povećanje bezbednosti vazdušnog saobraćaja i sprečavanje zloupotrebe vazdušnog prostora.

Prijava, najava, identifikacija i praćenje letenja bespilotnih vazduhoplova predstavlja problem na čijem se rešavanju intezivno radi, kako u Evropskoj uniji, tako i na svetskom nivou.

Ovaj rad predstavlja skromni doprinos u rešavanju problema vezanih za uspostavljanje bezbednog sistema kontrole letenja bespilotnih vazduhoplova.

Ključne reči:

informacioni sistem, kontrola letenja, bespilotni vazduhoplov, identifikacija.
\end{abstract}

\section{UVOD}

U okviru sistema za upravljanje bespilotnim vazduhoplovima u Republici Srbiji, Direktorat civilnog vazduhoplovstva Republike Srbije (u daljem tekstu DCV) vrši upis bespilotnih vazduhoplova u Evidenciju vazduhoplova, a na zahtev vlasnika ili operatera bespilotnog vazduhoplova. DCV formira i vodi ažurnu evidenciju upisanih bespilotnih vazduhoplova, izdaje odobrenje za upravljanje bespilotnim vazduhoplovima, i vodi evidenciju o zdravstvenoj osposobljenosti podnosioca zahteva, odnosno operatera sistema bespilotnog vazduhoplova. Sve relavantne podatke vezane za podnosioca zahteva za letenje bespilotnim vazduhoplovom prosleđuje na dalje nadležno postupanje jedinici Vojske Srbije za civilno-vojnu koordinaciju.

Nakon dobijanja zahteva za alokaciju vazdušnog prostora od strane operatera sistema bespilotnog vazduhoplova, jedinica Vojske Srbije za civilno-vojnu koordinaciju prosleđuje upit prema nadležnim državnim
Correspondence:

Dragan Vasiljević

e-mail:

vasiljevicdj68@gmail.com 
organima Republike Srbije za mogućnost odobrenja letenja bespilotnih vazduhoplova u traženom prostoru.

Osnovni zadatak Kontrole letenja Srbije i Crne Gore SMATSA doo Beograd u sistemu upravljanja bespilotnim vazduhoplovima u Republici Srbiji jeste koordinacija sa jedinicom Vojske Srbije za civilno-vojnu koordinaciju u cilju usklađivanja i odobrenja alokacije određenog dela vazdušnog prostora, odnosno dela vazdušnog prostora za koji je operater sistema bepilotnog vazduhoplova tražio alokaciju.

Prepoznajući narastajući značaj upotrebe bespilotnih vazduhoplova, nadležne civilne institucije usvojile su niz propisa kojima se ova oblast reguliše u normativnom smislu. Tako se poslednjim izmenama i dopunama Zakona o vazdušnom saobraćaju (kraj 2015. godine) u Republici Srbiji definiše pojam bespilotni vazduhoplov i daju smernice nadležnim organima za kontrolu njihove upotrebe. Takođe, 01.01.2016. godine stupio je na snagu i Pravilnik o bespilotnim vazduhoplovima, koji detaljno reguliše prostorne i vremenske uslove i ljudske i tehničke kapacitete neophodne za upotrebu ove vrste vazduhoplova. Ovim Pravilnikom precizirana je i kontrola letenja bespilotnih vazduhoplova na pretaktičkom nivou koja obuhvata podnošenje zahteva za upotrebu nadležnoj civilnoj instituciji, i postupanje date institucije po dobijenom zahtevu.

Većina zemalja sveta ne poseduje radarsko-računarska ili druga sredstva koja su u mogućnosti da otkriju, prate i dejstvuju po ciljevima tako male efektivne radarske površine. Dalje, nisu jasno propisane procedure po kojima treba da se vrši kontrola letenja bespilotnih vazduhoplova, a koje treba da obuhvataju postupak prijave početka i kraja upotrebe istih od strane korisnika, kao i postupak odobravanja, neodobravanja ili prinudnog prekidanja upotrebe u slučaju nepredviđenih situacija.

U radu je predstavljen koncept sistema za upravljanje bespilotnim vazduhoplovima, opisane su komponente, operativne mogućnosti i način određivanja efikasnosti ovih sistema, kao i mogućnost integracije kontrole letenja bespilotnih vazduhoplova u jedinstven sistem kontrole i zaštite vazdušnog prostora Republike Srbije.

\section{SISTEM UPRAVLJANJA BEZBEDNOŠĆU VAZDUŠNOG SAOBRAĆAJA}

Bezbednost u vazdušnom saobraćaju je stanje u kome su rizik od ugrožavanja života i zdravlja ljudi i prouzrokovanja štete imovini smanjeni i održavani na prihvatljivom nivou, stalnim uočavanjem opasnosti i kontrolom rizika od uočenih opasnosti.
Pružaoci usluga u vazdušnoj plovidbi, avio-prevoznici, operateri aerodroma, vazduhoplovno-tehničke organizacije koje se bave održavanjem vazduhoplova i drugi subjekti koje odredi Direktorat primarno, odgovorni su za bezbedno obavljanje svojih delatnosti ili pružanje usluga, a za bezbedno obavljanje poslova u okviru vazduhoplovnog subjekta odgovorni su i svi pojedinci koji u obavljanju svojih poslova utiču na bezbednost.

Radi usklađivanja delovanja organa, organizacija i vazduhoplovnih subjekata koji su odgovorni za bezbednost u vazduhoplovstvu i davanja preporuka kako da se ona poboljša, Vlada obrazuje Nacionalni komitet za bezbednost u vazduhoplovstvu, kao povremeno radno telo Vlade. Komitet koordinira aktivnosti na pripremi i izradi predloga Nacionalnog programa bezbednosti u vazduhoplovstvu, koga donosi Vlada.

Sistem upravljanja bezbednošću vazdušnog saobraćaja obuhvata organizaciju, procedure i sistem odgovornosti kojima se uspostavlja i održava prihvatljiv nivo bezbednosti u radu vazduhoplovnog subjekta, a funkcioniše kroz izvršavanje sledećih zadataka:

- upravljanje vazdušnim prostorom (ASM - Airspace Management);

- operativne usluge u vazdušnom saobraćaju (ATS - Air Traffic Services) i

- upravljanje protokom vazdušnog saobraćaja (ATFM Air Traffic Flow Management).

Upravljanje vazdušnim prostorom obuhvata dinamičnu raspodelu vremena korišćenja raspoloživog vazdušnog prostora između različitih kategorija korisnika vazdušnog prostora, zasnovanih na kratkoročnim potrebama.

Upravljanje vazdušnim prostorom obuhvata: fleksibilno korišćenje vazdušnog prostora, organizaciju vazdušnog prostora, razvoj i oblikovanje struktura vazdušnog prostora i druge funkcije koje su vezane za upravljanje vazdušnim prostorom.

\section{POJAM, KLASIFIKACIJA I OSNOVNE KARAKTERISTIKE BESPILOTNIH VAZDUHOPLOVA}

Terminologija koja se danas koristi za vazduhoplove bez ljudske posade još uvek nije jasno i/ili univerzalno definisana.

Naziv koji se tokom razvoja ovih uređaja najčešće koristio, posebno u stranim stručnim publikacijama zapadnog porekla, bio je Unmanned Aerial Vehicle (UAV), što bi u neposrednom prevodu značilo - vazduhoplovno vozilo bez posade. Struktura ovoga termina nije slučajna jer su 
vazduhoplovi bez ljudske posade u početku razvoja bili tek deo šireg tehnološkog koncepta besposadnih vozila, među kojima su se istovremeno razvijala i zemaljska i podvodna vozila [1].

Jedan od termina koji se često sreće u stručnoj literaturi je i Remotely Piloted Aircraft (RPA), što bi u neposrednom prevodu značilo - daljinski upravljana/ pilotirana letelica. Uz ovaj termin koristi se i pojam Remotely Piloted Aircraft System (RPAS). Ovde nije reč o alternativnom terminu, već se radi o pokušaju distinkcije između bespilotnih vazduhoplova kod kojih pilot ili operater sistema bespilotnog vazduhoplova u svakom trenutku ima upravljačku kontrolu nad vazduhoplovom, i drugih bespilotnih sistema kod kojih se vazduhoplov u određenim ili svim segmentima leta ponaša potpuno autonomno [2].

U stručnoj literaturi istočnog porekla u upotrebi se nalaze termini Беспилотный летательный апарат (БЛА) - konkretno za sami bespilotni vazduhoplov - i Беспилотные авиационные система (БАС) - za sistem u koji su pored vazduhoplova uključeni i uređaji za upravljanje i pomoćni uređaji [3].

U Republici Srbiji se za ovu vrstu uređaja najčešće koristi izraz bespilotna letelica (BL).

Ovakav naziv nije optimalno terminološko rešenje iz više razloga. Pre svega, takvim letelicama upravlja pilot koji se ne nalazi na samoj platformi, već na zemlji. Samim tim, interakcija između pilota i letelice u smislu davanja ulaznih vrednosti za aerodinamičke upravljačke površine i izlaznu snagu motora i potisak - postoji, te se ne može govoriti o nepostojanju pilota u upravljačkoj petlji. S druge strane, termin letelica je više kolokvijalan nego stručan pojam, koji je nastao najverovatnije kao pokušaj diferencijacije platformi bez ljudske posade od konvencionalnih platformi s posadom ili - vazduhoplova. Termin vazduhoplov nije određen postojanjem posade na samoj platformi, te predstavlja širok okvir u odnosu na način ostvarivanja uzgona i pogonsku grupu platforme, što istovremeno u potpunosti odgovara i tehničko-tehnološkoj prirodi vazduhoplova bez ljudske posade.

Imajući u vidu gorenavedeno, najprihvatljivija varijanta za uređaje ove vrste predstavlja termin bespilotni vazduhoplov.

Ovde svakako treba pomenuti i pojam „dron” koji se odomaćio u publicistici i medijima, i kao takav zaokuplja pažnju široke javnosti. Sam pojam se na naš jezik može prevesti kao „trut” (pčela, obad), dok se može naći i prevod „zujalica”. Iako se reč dron u zapadnoj terminologiji upotrebljava za naoružane bespilotne vazduhoplove, u poslednje vreme ovaj pojam vezuje se za mnogo širi krug uređaja ove vrste.
Ne postoji tačna i potpuna definicija pojma bespilotni vazduhoplov. Ovaj problem potiče od raznovrsnosti i mnogobrojnih načina izvedbi letećih objekata koji mogu da se svrstaju u ovu grupu uređaja. Takođe, ovaj problem sa sobom povlači i veliki broj određujućih osnovnih karakteristika bespilotnih vazduhoplova, što otežava njihovo precizno definisanje, ali i klasifikaciju. Osnovne karakteristike bespilotnih vazduhoplova, koje ujedno predstavljaju i kriterijume za njihovu klasifikaciju, mogu da budu: namena, značaj njihove upotrebe, nivo vazdušnog prostora u kome se koriste, autonomnost, princip rada pogonske grupe, tip i količina motora, aerodinamičnost, oblik i količina krila, uslovi baziranja, poletna masa, brzina, visina leta, taktički radijus dejstva itd. [4].

Osnovne komponente sistema bespilotnog vazduhoplova jesu: hardverski deo, softverski deo, sklop za elektronsku kontrolu i upravljanje, telemetrijski sklop i senzori [5]. Kategorije bespilotnih vazduhoplova u odnosu na tip, konstrukciju i pogonsku grupu prikazane su na Slici 1.

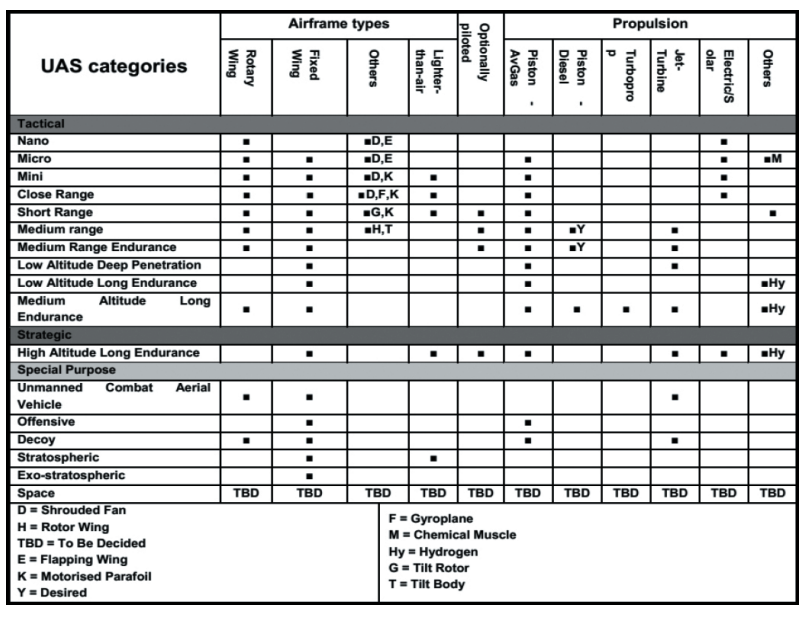

Slika 1. Klasifikacija bespilotnih vazduhoplova u odnosu na tip, konstrukciju i pogonsku grupu

\section{OPIS POSLOVA ELEMENATA SISTEMA ZA UPRAVLJANJE BESPILOTNIM VAZDUHOPLOVIMA U REPUBLICI SRBIJI}

Sistem za upravljanje bespilotnim vazduhoplovima u Republici Srbiji sastoji se od elemenata prema sledećem: Direktorat civilnog vazduhoplovstva Republike Srbije, jedinica Vojske Srbije za civilno-vojnu koordinaciju, Kontrola letenja Srbije i Crne Gore SMATSA doo Beograd, i sam sistem bespilotnog vazduhoplova (u daljem tekstu SBL). Podsistemi ovog sistema su: OJ GŠ VS, OJ MUP RS i BIA. 
U okviru sistema za upravljanje bespilotnim vazduhoplovima u Republici Srbiji, Direktorat vrši upis u Evidenciju vazduhoplova, na zahtev vlasnika ili operatera bespilotnog vazduhoplova, po ovlašćenju vlasnika. Formira i vodi ažurnu evidenciju upisanih bespilotnih letelica, izdaje odobrenje za upravljanje bespilotnim letelicama i vodi evidenciju o zdravstvenoj osposobljenosti podnosioca zahteva odnosno operatera sistema bespilotnog vazduhoplova. Sve relavantne podatke vezane za podnosioca zahteva za letenje bespilotnim vazduhoplovom prosleđuje na dalje nadležno postupanje jedinici Vojske Srbije za civilno-vojnu koordinaciju.

Nakon dobijanja zahteva za alokaciju vazdušnog prostora od strane operatera sistema bespilotnog vazduhoplova, jedinica Vojske Srbije za civilno-vojnu koordinaciju prosleđuje upit prema nadležnim OJ GŠ VS, MUP RS i BIA za mogućnost odobrenja letenja bespilotnih vazduhoplova u traženom prostoru.

Osnovni zadatak Kontrola letenja Srbije i Crne Gore SMATSA doo Beograd u sistemu upravljanje bespilotnim vazduhoplovima u Republici Srbiji jeste koordinacija sa jedinicom Vojske Srbije za civilno-vojnu koordinaciju u cilju usklađivanja i odobrenja alokacije određenog dela vazdušnog prostora, odnosno dela vazdušnog prostora za koji je operater sistema bespilotnog vazduhoplova tražio alokaciju [6].

\section{METODE MODELOVANJA INFORMACIONOG SISTEMA KONTROLE LETENJA BESPILOTNIH VAZDUHOPLOVA}

U ovom poglavlju dat je kratak opis metoda koje su korišćene pri izradi informacionog sistema za kontrolu letenja bespilotnih vazduhoplova, prema sledećem:

- metod funkcionalnog modelovanja;

- metod informacionog modelovanja i

- metod aplikativnog modelovanja.

\section{Metod funkcionalnog modelovanja}

Za efektivno funkcionisanje organizacije mora se identifikovati i upravljati mnogobrojnim, međusobno povezanim procesima. Modelovanje procesa omogućava dekompoziciju „poslovnih procesa” i planiranje potrebnih resursa za realizaciju procesa. Najvažnija korist u primeni modelovanja procesa je prototipski pristup kojim se na relativno brz i jednostavan način proveravaju alternativne ideje. Mnogo je jeftinije generisati model procesa, nego razviti novi informacioni sistem.
Za potrebe funkcionalnog modelovanja izrađen je dijagram konteksta koji predstavlja najviši nivo apstrakcije koji se dekompozicionim dijagramima prevodi u niži nivo apstrakcije. Svaka od podfunkcija podređenog dijagrama može kreirati svoj dijagram na nižem nivou. Na taj način, definišu se različiti nivoi apstrakcije, tj. na višim nivoima su opštije funkcije, koje se na nižim nivoima dekomponuju i detaljnije opisuju. Procesi na najnižem nivou koji se dalje ne dekomponuju nazivaju se primitivni procesi.

\section{Metod informacionog modelovanja}

Kada je dekompozicija sistema izvedena do poslednjeg nivoa tj. do nivoa "primitivnog procesa”, potrebno ga je detaljnije opisati. Opisivanje se izvodi informacionim modelovanjem definisanjem logičkog modela podataka.

Model podataka je pojednostavljeno predstavljanje realnog sistema preko skupa objekata (entiteta), veza između objekata i atributa objekata. Svaki entitet ima svoje osobine (atribute), a entiteti su međusobno povezani vezama (relacijama).

Osnovni objekti u logičkom modelu podataka su: entiteti, atributi i relacije. U fizičkom modelu podataka, osnovni objekti su: tabele, kolone i ograničenja (kao relacija) [7].

\section{Metod aplikativnog modelovanja}

Aplikativno modeliranje vezano je za definisanje fizičkog modela podataka, generisanje šeme baze podataka, izradu korisničke aplikacije.

Prilikom prevođenja logičkog modela u fizički dolazi do konverzije. Entiteti postaju tabele, atributi se definišu kao kolone, instance ili primerci postaju redovi, na preseku reda i kolone definišu se polja, kao i odgovarajuća ograničenja u zavisnosti od izabranog sistema za upravljanje bazom podataka.

Izrada aplikacije omogućava korisnički pogled na podatke, tj. da se definišu meniji, forme, upiti i izveštaji, i izvodi se na osnovu prethodno urađene šeme baze podataka, kao i konkretnih zahteva budućih korisnika. Specifikacija forme izvodi se za:

- definisanje menija;

- definisanje izgleda forme;

- definisanje upita i

- definisanje izveštaja.

Primer izrđene aplikacije za prijavu letenja bespilotnim vazduhoplovom dat je na Slici 2. 


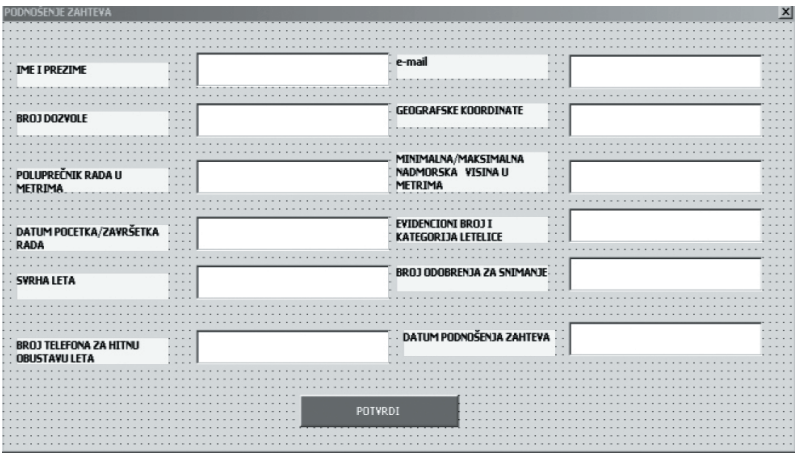

Slika 2. Prikaz aplikacije za prijavu letenja bespilotnim vazduhoplovom

Skladištenje podataka o registrovanim korisnicima bespilotnih vazduhoplova

Informaciona „inteligencija” objedinjuje metode, tehnologije i platforme za skladištenje podataka (eng. Data Warehausing), OLAP procesiranje podataka (eng. On-line Analytical Processing) i otkrivanje ,znanja” u podacima (eng. Data Mining), koje omogućava korisnicima kreiranje korisnih upravljačkih informacija iz podataka o pacijentima i organizaciji koji se nalaze disperzovani na različitim transakcionim sistemima, koji dolaze iz različitih internih i eksternih izvora [8].

U cilju vizuelizacije baze podataka, urađena je test baza podataka „Podnosioci zahteva za letenje bespilotnim vazduhoplovima” koja je korišćena kao primer u radu. Da bi se ona mogla koristiti, potrebno je sagledati njenu strukturu.

Baza podataka „Podnosioci zahteva za letenje bespilotnim vazduhoplovima" kreirana je u Microsoft Access-u i koristi se za čuvanje podataka o korisnicima bespilotnih vazduhoplova, s jedne strane, i za čuvanje podataka o karakteristikama bespilotnih vazduhoplova, $s$ druge strane. Za svakog korisnika određuje se status i kategorija kojoj pripada. Na osnovu ulaznih podataka i zahteva za alokaciju vazdušnog prostora, informacioni sistem izrađuje i prikazuje status odobrenih zona na osnovu raspoloživosti vazdušnog prostora. Zone za rad određuju se u odnosu na unete geografske koordinate, koje su centar kruga, a dimenzije kruga determinisane su poluprečnikom koji se izražava u metrima i meri se od centra kruga, do zahtevanih granica za letenje. Baza podataka „Podnosioci zahteva za letenje bespilotnim vazduhoplovima" sadrži pet tabela:

1. Tabela Podaci o korisnicima - Koristi se za čuvanje podataka o registrovanim licima koja imaju pravo pristupa sistemu za prijavu letenja bespilotnim vazduhoplovom;
2. Tabela Orijentacija - Koristi se za čuvanje podataka o koordinatama tražene zone za letenje, visinu leta i vreme trajanja leta;

3. Tabela Vreme izdatog odobrenja i podnošenja zahteva - Koristi se za čuvanje podataka o vremenu izdavanja odobrenja i podnošenja zahteva;

4. Tabela Podaci o letelici - Koristi se za čuvanje podataka o evidencionom broju i tehničkim karakteristikama letelice;

5. Tabela Podnošenje zahteva - Koristi se za čuvanje podataka o istoriji pacijenta.

$\mathrm{Na}$ Slici 3 prikazana je veza između definisanih tabela.

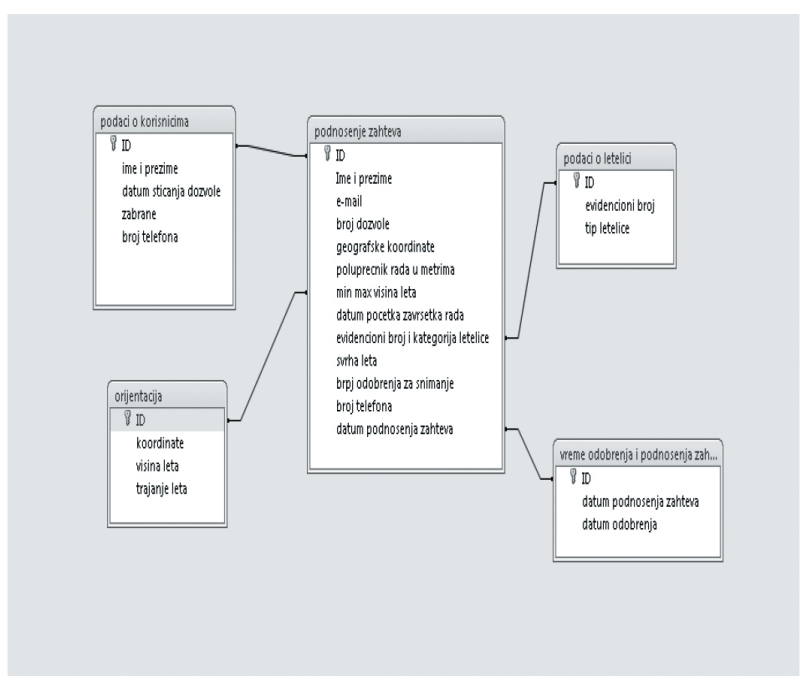

Slika 3. Prikaz veza između definisanih tabela

Tabela „Podnošenje zahteva” predstavlja logičko grupisanje podataka (svi podaci o korisnicima čuvaju se u Tabeli Podnošenje zahteva, dok se svi podaci o bespilotnim vazduhoplovima čuvaju u tabeli „Podaci o letelici”. Takođe, može se primetiti da svaka tabela čuva dve vrste podataka - izvorne podatke i relacione podatke.

Izvorni podaci predstavljaju stvarne podatke koji treba da se čuvaju (na primer, u tabeli „Podaci o korisnicima” su podaci o prezimenu i imenu korisnika, zabrane, broj telefona i sl.).

Osnovna namena baza podataka je dobijanje informacija na osnovu podataka koji se čuvaju u bazi podataka. Na primer, koja zona za letenje bespilotnih vazduhoplova je slobodna za letenje. Ovakvi zahtevi se u bazama podataka prevode u upite (eng. query) koji kada se izvrše prikazuju tražene informacije, s tim što se na karti iscrtava kružnica čiji je centar određen unetom geografkom širinom i dužinom, a poluprečnik rada određen unetim 
poluprečnikom u metrima. Na Slici 4 prikazana je aplikacija za prikaz i praćenje letenja bespilotnih vazduhoplova u određenim - alociranim delovima vazdušnog prostora Republike Srbije.

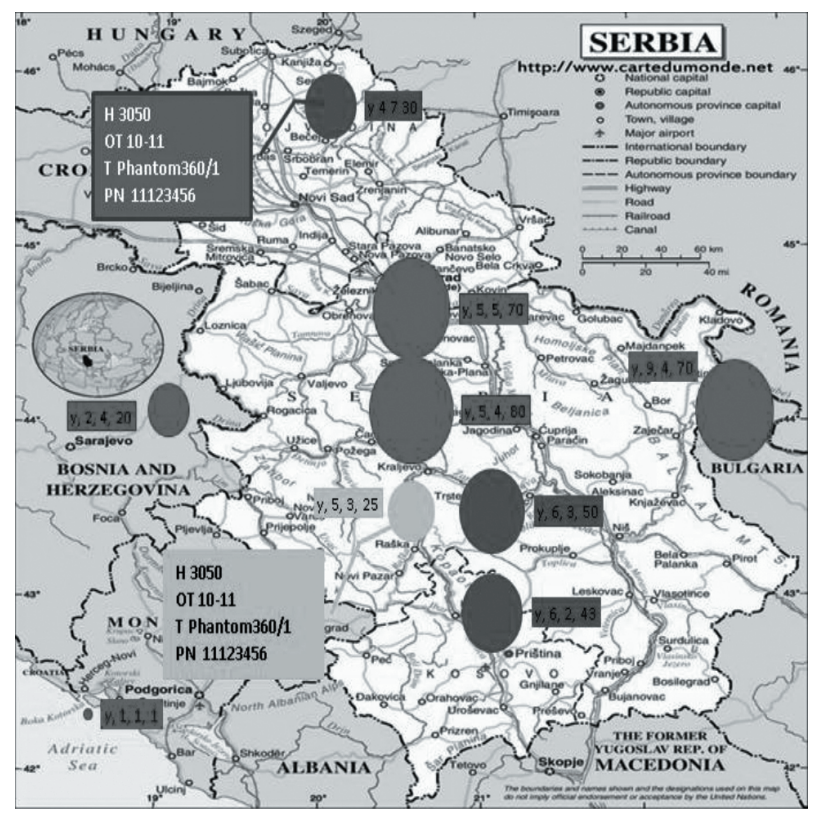

Slika 4. Prikaz aplikacije za kontrolu i praćenje letenja bespilotnih vazduhoplova

Takođe, predloženi model informacionog sistema za kontrolu i praćenje letenja bespilotnih vazduhoplova poseduje sposobnost da se automatski obeleže alocirane zone, u zavisnosti od statusa npr. crvena boja označava da se ne odobrava letenje u traženoj zoni (razlog može biti različit npr. pogrešno unete koordinate, preklapanje zona letenja od strane više korisnika, zona zabrane letenja i sl.). Narandžasta boja označava da je tražena zona odobrena za letenje ali još uvek nije aktivna. Plava boja označava aktivne zone u kojima se trenutno odvija letenje.

Pored navedenog, u vidu tablice prikazani su podaci za svaku zonu u kojoj je planiran let ili u kojoj se odvija letenje. Tabele podataka sadrže podatke o:

- visini leta;

- vremenu trajanja leta;

- vrsti letelice i

- broj telefona za hitnu obustavu leta.

\section{ZAKLJUČAK}

Dosadašnja iskustva u aktivnostima vezanim uz integraciju bespilotnih vazduhoplova u civilni vazdušni prostor upućuju na to kako bi najveće regulatorne prepreke mogle biti vezane uz „označenu” odgovornost, odnosno potrebu da se u svakom trenutku mora jasno znati ko je odgovoran za sigurnost operacije u kojoj učestvuje bespilotni vazduhoplov. Nije slučajno što se u NATO frazeologiji nametnuo izraz „označeni operater bespilotnih vazduhoplova”, upravo sa ciljem kako bi se na taj način operater, u komunikaciji s odgovarajućim službama kontrole letenja, pozicionirao kao subjekt koji je odgovoran za vazduhoplov kojim upravlja.

U cilju sigurne integracije bespilotnih vazduhoplova u kontrolisani vazdušni saobraćaj, Eurocontrol razvija zahteve za bespilotne vazduhoplove u ATM okruženju, koji će se sastojati od skupa interoperabilnih kriterijuma za operativna odobrenja i sertifikaciju. Ti zahtevi pretpostavljaju kako će se bespilotni vazduhoplovi u potpunosti prilagoditi postojećem ATM sistemu, pre nego da se taj sistem na bilo koji način prilagođava bespilotnim vazduhoplovima.

Ovaj rad predstavlja skromni doprinos u razvoju informacionog sistema za kontrolu letenja bespilotnih vazduhoplova, čime bi se u znatnoj meri poboljšala bezbednost svih učesnika u vazdušnom saobraćaju.

\section{LITERATURA}

[1] Dept. Airborne Air Defence, Einsteinstr. 20 D-85521 Ottobrunn, Integration of Unmanned Aerial Vehicles into Future Air Traffic Management Version 1.17 th December 2001.

[2] Backlund A.: The definition of system, 2000, In: Kybernetes Vol. 29 nr. 4, pp. 444-451.

[3] Tkačov D.A.; Sivaško S.B.: Klasifikacija bespilotnih avijacijskih sistema, Nauka i vojna bezbednost, broj 3/2015, Izdavački zavod Naučnoistraživačkog instituta Republike Belorusije, Minsk, 2015.

[4] Eurocontrol, Specifications for the Use of Military Unmanned Aerial Vehicles as Operational Air Traffic Outside Segregated Airspace, Eurocontrol, 2007.

[5] Chris Johnson, The safety research challenges for the air traffic management of unmanned aerial systems (UAS), Prezentacija, Department of Computing Science, University of Glasgow, Škotska.

[6] Pravilnik o bespilotnim vazduhoplovima („Službeni glasnik RS“, broj 108/15)

[7] Curtis Smith: Visual Basic 6 - Programiranje baza podataka, 2002.

[8] David Sceppa: Programming ADO, 2000. 